\title{
KNOWLEDGE AND ATTITUDE OF STUDENTS REGARDING THE FORMAL MENTORSHIP PROGRAMME FOR MEDICAL EDUCATION
}

\author{
Saima Abid', Ghulam Sarwar², Bilqis Hassan ${ }^{3}$, Naveeda Sarwar $^{4}$, Tariq Masood $^{5}$, Zahra Qazi $^{6}$, Samiullah $^{6}$, \\ Abdul Basit Khan ${ }^{6}$, Nighat Yasmin ${ }^{6}$
}

1. Associate Professor, Community Medicine Department, PIMC Peshawar, Pakistan.

2. Professor Community Medicine Department, PIMC Peshawar, Pakistan.

3. Senior Lecturer, Community Medicine Department, PIMC Peshawar, Pakistan.

4. Clinical Psychologist, Community Medicine Department, PIMC Peshawar, Pakistan.

5. Assistant Professor, Haematology, NWSMedicine, Peshawar, Pakistan.

6. Student, Community Medicine Department, PIMC Peshawar, Pakistan

Correspondence: Saima Abid, Cell: 03410002272, Email: address saimabiddr@gmail.com

\begin{abstract}
Background: Medical students have a very extensive curriculum and a demanding time period during their undergraduate studies (1-5 years). Research has shown that medical students experience a high level of stress affecting their social, emotional as well as mental health. According to many studies formal mentoring is considered as a key to overcome these problems. Currently Khyber Pakhtunkhwa is deficient in formal mentorship program for medical education, the purpose of this article was to determine the presence of the programme and to establish the basis for formal mentoring with in medical colleges.

Methods: The study was a descriptive cross-sectional study. A total of 300 students, both male and female were selected from two medical colleges on convenient basis. Sample size was determined by the Cochran equation with 95\% confidence interval. A closed ended, original questionnaire was developed in English language from valid questionnaires of similar studies conducted in past. Data was analysed using MS Excel and SPSS version 22.

Results: Total of 150 Data of $270(90 \%)$ respondents was analysed after drop outs. Among the study participants 114 $(42.2 \%)$ students had No knowledge about mentoring for medical education; 153 (96.8\%) students responded that mentoring would help in the academic to professional development of the students. Majority of the students $(n=152$, $96.2 \%$ ) respondents stated that there was a strong need of formal mentorship programme in their medical college.

Conclusion: Knowledge regarding function and structure of mentorship program among students was below average. However a strong positive attitude to initiate the mentorship Programme was observed among respondents.

Keywords: Mentorship, private medical college, public sector, knowledge, attitude.
\end{abstract}

\section{Introduction}

Mentorship has been defined by Berk et al. in 2005 as "a relationship that may vary from informal/short-term to formal/long-term in which faculty with useful experience, knowledge, skills, and/or wisdom offers advice, information, guidance, support, or opportunity to another faculty member or student for that individual's professional development" (1). It is a useful educational tool. Fundamentally, a mentor facilitates personal and professional growth through the sharing of learned knowledge and insight (2). Formal mentorship for medical education started in USA in 1970s (2). More recent medical history shows that mentoring positively affects professionalism. Over the past two decades, the prospect of mentoring has broadened and become a more vital part of medical education (3).
South East Asia provides medical education through more than 500 medical colleges (4). In Pakistan, a medical school is more often referred to as a medical college. According to Pakistan Medical and Dental Council, there are a total of 108 medical colleges in Pakistan (41 public and 67 private). Khyber Pakhtunkhwa caters 19 (9 Public and 10 private) medical colleges. Out of it district Peshawar contains eight medical colleges.

Certain Medical colleges like Dow International Dental College Karachi, Rawalpindi Medical College, Behria University, Peshawar Medical College etc. has had a structured mentorship programme for their students for the last one decade (5). Several related studies have been published time to time. The purpose of this study was to survey the existence and perception of formal 
mentorship for medical education in medical colleges of district Peshawar of Khyber Pakhtunkhwa. Findings of current research are deemed to provide an insight regarding the subject and forms basis for implementation of responded programme in medical colleges of district Peshawar.

\section{Methodology}

A descriptive cross-sectional study design was selected for the study. A sample size of 300 students was determined employing Cochrane Equation for sample calculation. Students of both genders, aged 18-24 years, belonging to all ethnic groups and willing to participate in the study were included. Students with acute or chronic illnesses or on leave were excluded. Study population was approx. 4500 medical students of eight medical colleges in District Peshawar. An original questionnaire comprising closed ended dichotomous questions and Likert scale was developed from valid questionnaires used in similar studies conducted previously. For comprehensive assessment of the questionnaire, pilot testing and peer review was done. The questionnaire covered current status of formal mentoring in respective colleges, the level of knowledge among students regarding the program and their aptitude. Students who scored above $70 \%$ in knowledge based questions were considered as having sound knowledge about the programme and its benefits. Two medical colleges were selected (one each from public and private sector). A total of 150 students were selected from each college on convenient basis, after acquisition of an informed consent in writing. In order to generalise the results 30 students were selected from each class. The questionnaires were handed over to the students and recollected on the next day. Improperly filled questionnaires were excluded from the study. The data collected was recorded and analysed using MS Excel and SPSS version 22. Frequencies were calculated for nominal variables whereas means and standard deviations were sorted for the continuous ones. Onesample t-test was used for assessment of level of knowledge among the study participants. Chi-square Goodness-of-Fit test was used for statistical analysis of dichotomous nominal data.

\section{Results}

Of the total 300 students enrolled into the study, 122 $(45.2 \%)$ were male and $148(54 \%)$ were female. The participants included 60 students from 1 st year, 55 from 2nd yr, 48 from 3rd year, 47 from 4th year and 60 from final year. Questionnaires of 30 students were disregarded for being inappropriately filled; data of 270 students was further analysed. The mean age of study participants was $20 \pm 2$ years.

\section{Familiarity of students \& Existence of Formal Mentorship Program}

It was found that 87 students $(32.2 \%)$ had ample knowledge about mentorship programme, among the participants, 71 students $(26.2 \%)$ responded that they had little bit knowledge about formal mentorship for medical education; 112 students $(41.4 \%)$ responded that they do not know anything about formal mentorship. Rest of the survey was carried out on 158 students (112 being unware of mentorship program were excluded from further survey).

Majority of the students $(n=83,52.5 \%)$ responded that no formal mentorship programme existed in their college while $95(60.1 \%)$ replied that they did not have any past experience of any kind of informal mentoring (figure 1). Only $42(26.6 \%)$ students responded that they were confident about their adjustment into demanding medical college life when they newly entered medical colleges.

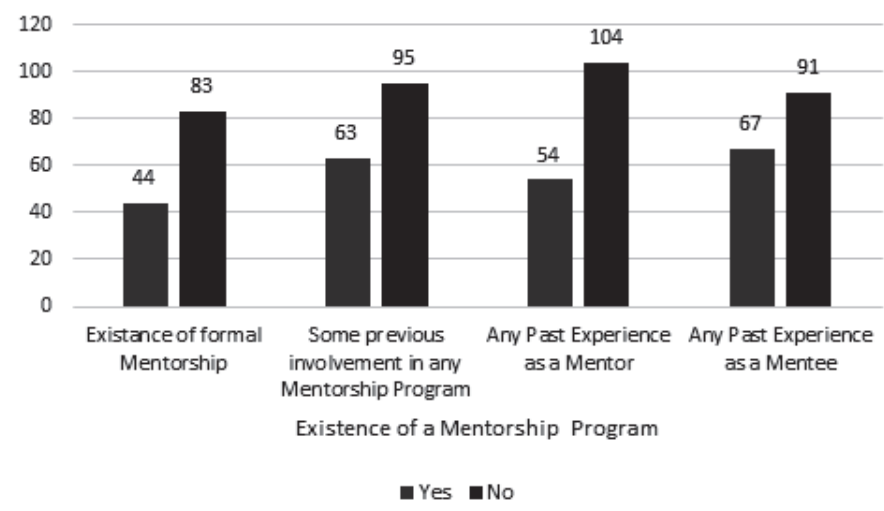

Figure 1: Familiarity and existence of formal mentorship Program

Knowledge of the students

Table 1 is self-explanatory showing knowledge of the students with most $(42 \%)$ having knowledge about the mentorship programme and knowing that the mentorship was helpful in identifying the psychological problems..

\section{Table 1: Knowledge based assessment parameters}

\begin{tabular}{|l|c|c|c|c|}
\hline Knowledge about Mentorship & Yes & \% age & No & \% age \\
\hline Do you have any Knowledge About mentorship & 87 & 31.9 & 114 & 42.2 \\
\hline Mentorship Improves self Confidence & 151 & 95.6 & 7 & 4.4 \\
\hline Mentorship Improves Social Skills & 150 & 94.9 & 8 & 5.1 \\
\hline $\begin{array}{l}\text { Mentorship Helps In Academic to Professional } \\
\text { Development }\end{array}$ & 153 & 96.8 & 5 & 3.2 \\
\hline $\begin{array}{l}\text { Mentorship Improves Analytical / Problem } \\
\text { Solving Skills }\end{array}$ & 149 & 94.3 & 9 & 5.7 \\
\hline Mentorship improves Time Management Skills & 149 & 94.3 & 9 & 5.7 \\
\hline Mentorship Affects Interests and Vision & 150 & 94.9 & 8 & 5.1 \\
\hline $\begin{array}{l}\text { Mentorship Improves scientific communication } \\
\text { skills }\end{array}$ & 143 & 90.5 & 15 & 9.5 \\
\hline Mentorship Identifies Psychological problems & 91 & 57.6 & 67 & 42.4 \\
\hline $\begin{array}{l}\text { Mentorship Improves attitude towards learning } \\
\text { and working }\end{array}$ & 143 & 90.5 & 15 & 9.5 \\
\hline Mentee Gets Benefits & 147 & 93 & 11 & 7 \\
\hline
\end{tabular}

Value of T test was found less than .001.

\section{Attitude}

In the present survey, 115 (72.8\%) students responded that the mentor should be a senior faculty member while $43(27.2 \%)$ responded that mentors should be fresh young faculty members. Among the participants, 104 $(65.8 \%)$ responded that it is fine if the mentoring is cross-gender. A majority of the students ( $n=81,51.3 \%)$ responded that formal mentoring activity be carried out 
once a week, $40(25.3 \%)$ students suggested that the activity be carried out once in two weeks while 37 (23.4 $\%)$ students opted that formal mentorship meeting should be conducted when demanded by the mentees.

A significant number of students $(n=104,65.5 \%)$ preferred group-based setting for mentoring, while 54 $(34.2 \%)$ students believed that formal mentorship is better held in one-to-one setting. Regarding confidentiality of the process, $72(45.6 \%)$ students suggested that only important information can be shared with the parents, $30(19 \%)$ students believe that no information be shared with the parents while $56(35.4 \%)$ students opted that all the information be shared with the parents.

Regarding skills development, 56 (35. 4 \%) students suggested that the mentor should focus on academic to professional development, $49(31 \%)$ students preferred focussing on social \& scientific communication skills, 26 $(16.5 \%)$ students prioritised time management skills while $27(17.1 \%)$ students preferred that the mentors should focus analytical and problem solving skills of the mentees.

A majority of the students ( $n=152,96.2 \%)$ respondents stated that there was a strong need of formal mentorship Programme in their medical colleges; 6 (3.8\%) students negated need of formal mentorship program in their Medical College.

\section{Discussion}

Progress of students in higher studies is a main focus globally. It is the need of the day to enhance the support extended to students to help maximize their progress. Medical students have a very extensive curriculum and a demanding profession. To overcome these stresses formal mentoring is suggested (5). Current study was conducted to determine the presence of the mentorship program in the selected Medical colleges. It was identified that there was no structured mentorship program in both medical colleges. Only one third of the participants said that they have little bit knowledge about mentorship. These participants were included in the survey further. Knowledge of these participants regarding mentorship program was assessed. Adjustment to the new environment of the medical colleges is a challenging job, as medical students have a very extensive curriculum and demanding schedule which can cause emotional and psychological issues. Current study identified that $74 \%$ students were not confident about adjustment into medical environment after entering in medical college. A majority (95\%) of the students said that mentorship is an effective tool to boost self-confidence of newly admitted students to settle in medical college environment. This finding is consistent with the findings of the study conducted by JO ANN which cited that the most significant stressor for nurses were to fit into the academic environment (6). In another study conducted by one acute trust and one community trust also mentioned that adjustment to the placement and integration into the teamwork were the aspects students mainly needed support with (7). Current study focuses on faculty- student mentoring. It identified that $112(41.4 \%)$ students have no past experience of any sort of mentorship program. A similar study was conducted by Martine Quensnet et al on knowledge and practices of Canadian master of physical therapy students regarding peer mentoring (8). The Canadian study focuses on Peer mentoring rather than facultystudent mentoring. Developed countries are generally believe to have more knowledge about mentoring but unexpectedly in Canada in this particular study $(68.7 \%$ ) more students claim that they have no past experience of mentorship compare to current study. Current study reveal that $94.4 \%$ students believed that mentorship can improve social and $90.5 \%$ said that it can improve scientific communication skills of the students. Another study conducted by Cameron $C$ et al identified that trainees were keen to learning scientific communication skills through mentorship program (9). In current study important aspect such as professional development was discussed. It was noticed that $96.8 \%$ students agreed that mentorship can help in Academic to professional development of the students. $90.5 \%$ students believe that Mentorship Improves attitude towards learning and working. In another study, $65.9 \%$ of the respondents believed that peer mentoring help in from student to professional transition (8).

In current study students believe that Mentorship can help in personal development i.e. Social and Time Management Skills along with Interests and Vision. Similarly 11 surveys which address the requirements for being an effective mentor, recorded that the mentor should assist in the mentee's personal development (10). In the present survey, $115(72.8 \%)$ students responded that the mentor should be a senior faculty member. this finding is supported by Kosoko-Lasaki et al. who suggested that a useful and feasible model for a student mentoring program could be designed using tiers, i.e. younger students are mentored by advanced students, and advanced students are mentored by faculty members or senior physicians/researchers (11). Current study discuss confidentiality, with respect to sharing of information with the parents, where almost half $72(45.6 \%)$ students suggested that only important information can be shared with the parents, 30 (19\%) students believe that no information be shared with the parents. A study conducted in Bahria Medical University Karachi regarding Ethical issues related to mentoring, the matter of general confidentiality from Mentors part was discussed, where $90 \%$ of the Mentors said that they will keep the trust of the mentee and will never disclose any information with anyone (12). Medical students are prone to have psychological problems i.e. depression, anxiety etc. according to current research about $57.6 \%$ students said that mentorship has the potential to identify psychological problems among mentees. This idea is endorsed by Subha Ramani, et al., who believed that mentors should be trained in recognition of 
psychological problems that need referral to professionals such as psychologists or councillors (13). Majority of the students (93\%) in the current study stated that mentee will be benefited by the mentoring program in medical school. In a previous review, it was stated that mentee will be benefited if mentee is active in agenda setting, follow through, accept criticism and able to assess performance and benefits of the program (10). Khyber Pakhtunkhwa is a conservative society where male and female is a segregated community but surprising results were observed when participants were asked about gender of the mentor, $65.8 \%$ said that its ok if mentoring is cross- gender, while only $34.2 \%$ said that mentors should be of same gender. These results are consistent with research conducted by Jakson et al., where same gender match between mentor and mentee was not felt to be essential (14). Current study shows a strong positive attitude towards mentoring for medical education, where $(96.2 \%)$ students sad that there is a need of a mentorship program in their medical college. In another study by Saad Alqahtain et al., similar findings i.e. $92 \%$ students said that there is a strong need for mentoring (15). In current study most of the participants suggested the group setting should be introduced for mentoring. In contrast to our findings, it was suggested by Esther Frei et al that for students pursuing an academic career, a one-to-one mentorship in research proves most effective (10). One of the key finding of current study shows a strong positive attitude toward mentorship programme. This finding concurs with most of the existing evidence supporting the concept of mentorship(8).

\section{Conclusion}

Knowledge of students regarding formal mentoring for Medical education, in both public and private medical colleges is limited. Medical students showed a positive attitude towards the need and implementation of a mentorship programme in their medical colleges.

\section{References}

1. Berk RA, Berg J, Mortimer R, Walton-Moss B, Yeo TP. Measuring the Effectiveness of Faculty Mentoring Relationships. Academic Medicine. 2005;80(1):66-71.

2. Sanfey H, Gantt NL. Career development resource: academic career in surgical education. The American Journal of Surgery. 2012;204(1):126-9.

3. Sadideen H, Kneebone R. Practical skills teaching in contemporary surgical education: how can educational theory be applied to promote effective learning? The American Journal of Surgery. 2012;204(3):396-401.

4. Ragins BR. Barriers to Mentoring: The Female Manager's Dilemma. Human Relations. 1989;42(1):1-22.

5. Usmani A. Pakistan: Ethical implications in mentoring medical students. Asian Human Rights Commission, Opinion, 2011.
6. Sawatzky JA, Enns CL. A mentoring needs assessment: validating mentorship in nursing education. Journal of professional nursing : official journal of the American Association of Colleges of Nursing. 2009;25(3):145-50. Epub 2009/05/20.

7. Mclntosh A, Gidman J, Smith D. Mentors' perceptions and experiences of supporting student nurses in practice. International Journal of Nursing Practice. 2013;20(4):360-5.

8. Quesnel M, King J, Guilcher S, Evans C. The Knowledge, Attitudes, and Practices of Canadian Master of Physical Therapy Students Regarding Peer Mentorship. Physiotherapy Canada. 2012;64(1):65-76.

9. Cameron $\mathrm{C}$, Collie $\mathrm{CL}$, Baldwin $\mathrm{CD}$, Bartholomew LK, Palmer JL, Greer M, et al. The Development of Scientific Communication Skills: A Qualitative Study of the Perceptions of Trainees and Their Mentors. Academic medicine : journal of the Association of American Medical Colleges. 2013;88(10):10.1097/ACM . 0b013e3182a34f36.

10. Frei E, Stamm M, Buddeberg-Fischer B. Mentoring programs for medical students - a review of the PubMed literature 2000 - 2008. BMC Medical Education. 2010;10(1).

11. Kosoko-Lasaki O, Sonnino RE, Voytko ML. Mentoring for women and underrepresented minority faculty and students: experience at two institutions of higher education. Journal of the National Medical Association. 2006;98(9):144959. Epub 2006/10/06.

12. Ambreen $U$, Quratulain $\mathrm{O}$, Syed Tipu S. Mentoring undergraduate medical students: Experience from Bahria University Karachi. J Pak Med Assoc. 2011;61(8):790-4.

13. Ramani S, Gruppen L, Kachur EK. Twelve tips for developing effective mentors. Medical Teacher. 2006;28(5):404-8.

14. Jackson VA, Palepu A, Szalacha L, Caswell C, Carr PL, Inui T. "Having the right chemistry": a qualitative study of mentoring in academic medicine. Acad Med. 2003;78(3):328-34. Epub 2003/03/14.

15. Al Qahtani S. Students' knowledge of, and attitudes toward, mentoring: a case study at the Master's Program in Health and Hospital Administration. Advances in Medical Education and Practice. 2015;6:149-52. 